\title{
Selected Personal Factors as Predictors of Quality of Life of Cancer Patients in Southwestern Nigeria
}

\author{
Alice Obianiberi Ntekim ${ }^{1}$, Chioma Christiana Asuzu ${ }^{1}$, Jonathan Ohiorenuan Osiki ${ }^{1}$, \\ Atara Isaiah Ntekim ${ }^{2, *}$ \\ ${ }^{1}$ Department of Guidance and Counselling, University of Ibadan, Ibadan, Nigeria \\ ${ }^{2}$ Department of Radiation Oncology, University of Ibadan, Ibadan, Nigeria \\ Email address: \\ aliceoby@gmail.com (A. O. Ntekim), chiomasuzu20@yahoo.com (C. C. Asuzu),kimata2000@hotmail.com (A. I. Ntekim) \\ ${ }^{*}$ Corresponding author
}

\section{To cite this article:}

Alice Obianiberi Ntekim, Chioma Christiana Asuzu, Jonathan Ohiorenuan Osiki, Atara Isaiah Ntekim. Selected Personal Factors as Predictors of Quality of Life of Cancer Patients in Southwestern Nigeria. Journal of Cancer Treatment and Research.

Vol. 8, No. 2, 2020, pp. 29-33. doi: 10.11648/j.jctr.20200802.11

Received: February 29, 2020; Accepted: March 13, 2020; Published: March 31, 2020

\begin{abstract}
The incidence of cancer across the globe has shown that the disease is a leading cause of death worldwide; and it accounted for 7.6 million deaths, which is about $13 \%$ of all deaths in 2018. Also, deaths from cancer worldwide are projected to be rising, with an estimated 12 million deaths in 2030. In spite of the efforts of stakeholders to control the prevalence and incidence of cancer, there still increase in reported cases of cancer incidence in Nigeria. Previous studies mainly focused on psychological and social variables as they affect cancer and cancer patients; while little concentration was made on personal factors of age, gender, marital and employment status in relation to quality of life of cancer patients, particularly in Nigeria. This study, therefore, examined personal factors as predictors of quality of life of cancer patients in Southwestern Nigeria. The study adopted descriptive survey design of correlational type. The population for this study consisted of all the diagnosed cancer patients who are attending clinics in the South West of Nigeria. Purposive sampling technique was employed to select 312 patients who were willing and able to participate in the study. A validated questionnaire was used for data collection; which yielded a reliability value of 0.88 . Data were analyzed using frequency counts and percentages for demographic characteristics, while multiple linear regression was used to test the hypotheses at 0.05 alpha level. There was a significant joint prediction of personal factors on quality of life of cancer patients in Southwestern Nigeria $\left(F_{(4,307)}=101.078 ; p<0.05\right)$. Age $(\beta=0.275, \mathrm{p}>0.05)$, gender $(\beta=0.537, \mathrm{p}>0.05)$, employment status $(\beta=0.236, \mathrm{p}>0.05)$ and marital status $(\beta=0.242, \mathrm{p}>0.05)$ independently had no significant prediction on quality of life of cancer patients in Southwestern Nigeria. There was a significant joint prediction of personal factors on quality of life of cancer patients in Southwestern Nigeria. It was also concluded that age, gender, employment and marital status independently had no significant prediction on quality of life of cancer patients in the study area.
\end{abstract}

Keywords: Personal Factors, Quality of Life, Cancer Patients

\section{Introduction}

The incidence of cancer across the globe has shown that the disease is a serious public health issue. It has constituted burden to various individuals, families and the society at large. According to American Cancer Society (2020), cancer is a major public health concern as the incidence of various types of cancer continues to increase. It is a leading cause of death worldwide; and it accounted for 9.5 million deaths (around 13\%) of all deaths in 2018 [1]. The International Agency for Research on Cancer (IARC, 2010) projected a worldwide estimate that, new cases of cancer could increase to almost 21.4 million in 2030 and that 13.2 million people would die from the disease [2].

Cancer occurs world-wide with varying incidence. The highest incidence is in Western countries like the USA where the incidence is 242 persons per 100,000 population; while developing countries like Nigeria have lower incidence of about $100 / 100,000$ population (2). More than $70 \%$ of all 
cancer deaths occurred in low and middle-income countries including Nigeria, where resources available for prevention, diagnosis and treatment of cancer are limited or non-existent [3]. The commonest cancers in Nigeria include breast, cervical, prostate, colorectal, liver cancer and non-Hodgkin lymphoma (NHL) [4,5]. These cancers occur in varying proportions with breast cancer being the commonest. The pattern is similar in the Southwestern Nigeria where the available figure is a 5- year estimate (2005-2009) of 5,094 cases as reported by Awodele and colleagues (2011) [6]. However, in 2012, a total of 3,393 cancer cases were reported in Ibadan Centre Registry over a two year period [7].

With advances in medicine, cancer is now more likely to be a chronic rather than a terminal illness. Some of these advances include introduction of new equipment for better diagnosis and treatment, new diagnostic tests for early detection and monitoring of patients and new drugs for more effective management. Even though, cancer diagnosis has tremendous consequences for most persons who experience it, the very first encounter with a diagnosis of the malignant disease arouses more intense emotional reactions than with any other disease. Thus the focus of the medical field is moving from simple life preservation towards general health promotion [8].

This implies that individuals now live longer with such health conditions and quality of their lives, rather than just being alive is equally germane. Living with a chronic disease like cancer, is a demanding experience that can affect multiple aspects of an individual's life, such as social, family and occupational functioning [9]. Thus, quality of life (QoL) is presently an important outcome factor in oncological research. Cancer is often associated with terms such as burden, struggle and suffering. This suggests that coping with the symptoms, diagnosis and treatment of cancer is a major life stressor. Although, cancer diagnosis and therapy as well as outcome measures have been improving, the negative image of cancer has not changed as it is still being associated with death and suffering therefore undermining their overall quality of life [10].

Quality of life deals with an individual's perception of their own position in life, in the context of the culture and value systems in their life and in relation to their goals, expectations, standards and concerns [10]. This emphasizes the multi-dimensional and subjective nature of QoL, as well as the breadth of its scope, since it borders on all aspects of one's life. These aspects include emotional considerations, social functioning and physical functioning among others.

Quality of life as a measure is important for planning clinical care of patients, outcome measurement in clinical trials and health services management. It is also relevant in health needs assessment of populations in descriptive studies; and for resource allocation and health economics. There is the need to study factors that predict such an important outcome. Socio-demographic factors have high impact on health and quality of life. In the general non-cancer population, Health related Quality of Life (HRQoL) depends on a number of factors, such as co-morbidities, sex and age $[11,12]$. It has also been indicated that chronic medical conditions increase the risk for unemployment which may result in a lower quality of life [13]. Consequently, it is dangerous to ignore the quality of life of cancer patients in order to avoid mental, emotional and social consequences that can affect the overall wellness of such patients. There is little concentration of the previous reports on quality of life of cancer patients and socio-demographic factors namely age, gender, marital status and employment status which are relevant indicators of quality of life of cancer patients, most especially in developing countries; hence the need to highlight the influence of these factors. The aim of this study was to examine how personal factors predict quality of life of cancer patients in Southwestern Nigeria. Our hypothesis was that there will be no significant joint and relative prediction of personal factors (age, gender, employment status and marital status) on quality of life of cancer patients in Southwestern Nigeria. This study was carried out with the following objectives: 1) To examine joint predictive capacity of personal factors (age, gender, employment status and marital status) on the quality of life of cancer patients in Southwestern Nigeria. 2) To examine the relative predictive capacity of personal factors of age, gender, employment status and marital status on the quality of life of cancer patients in Southwestern Nigeria.

\section{Methods}

Descriptive survey design of correlational type was used for the study. This study investigated the causal modelling and predictive capacity of endogenous variables (age, gender, marital status and employment status) on the criterion variable (quality of life of cancer patients). This design was considered appropriate by the researcher since no variable was subjected to manipulation in an experimental condition.

The population for this study consisted of all diagnosed cancer patients who attended clinics in the South West of Nigeria. South Western Nigeria is made up of six states namely Ekiti, Lagos, Ogun, Ondo, Osun and Oyo states. The total population of the region is estimated at 30 million people; who are occupying a land mass of about 76,852 square Kilometers. It is majorly a Yoruba language speaking area, although there are different dialects even within the same state. The estimated cancer incidence over a 5- year period (2005-2009) in the region was reported to be 5,094 cases [6].

In selecting the samples for this study, three states were purposively selected out of the six states in the South-West (Lagos, Ogun and Oyo) where there are major cancer centers and cancer patients mostly receive treatment and support after diagnoses in these three centers. The centres used were Lagos University Teaching Hospital (LUTH), University College Hospital (UCH), Ibadan and Federal Medical Centre (FMC) Abeokuta Nigeria.

The patients who were willing and able to participate were included in the study after obtaining informed consent. The study was approved by the Ethics Committees of the three hospitals. Patients aged 18 and above who gave consent for the study, had confirmation of cancer disease by pathologists' 
report and had performance status defined by Eastern Cooperative Oncology Group (ECOG) 0-3 were included in the study. However, patients with non-solid tumours (leukaemia) were excluded from the study. In addition, patients with other serious uncontrolled medical conditions that the investigators felt might compromise study participation including, but not limited to, ongoing or active infection; HIV-positive patients, uncontrolled hypertension, symptomatic congestive heart failure, unstable heart disease, uncontrolled Diabetes mellitus, or psychiatric illness/social situations that would limit compliance with study requirements were excluded. In the same vein, very ill patients including patients on strictly palliative care as well as post treatment patients on routine follow up visits were excluded from the study.

Version 3.0 of the European Organisation on Research and Treatment of Cancer (EORTC) questionnaire was used as instrument for the study. The questionnaire which is also known as Quality of Life Questionnaire (QLQ-C30) is a quality-of-life instrument developed for use in international clinical research in oncology and regarded as the most widely used QoL instrument among cancer patients. The questionnaire was divided into two sections, namely, A and B. Section A covered socio-demographic characteristics of the respondents, section B entailed Quality of Life Scale. The socio-demographic characteristics of the respondents covered in section A include; age, gender, employment status and marital status. Section B was used to elicit information on dependent variable of quality of life which covered physical well-being, emotional, financial and global quality of life. A pilot study was conducted among patients in a different hospital (Obafemi Awolowo Teaching hospital, Ile Ife Nigeria) for revalidation. From the revalidation process, the entire quality of life items was reduced to ten items; and the scale (short form) recorded a Cronbach Alpha of 0.88 .

The completed copies of questionnaire were collated, coded and analysed using both descriptive and inferential statistics. Data were analyzed using the Statistical Package for Social Sciences program (SPSS), version 21. Frequency count and percentages were used to analyze demographic data. Inferential statistics of multiple linear regression was used to test the hypotheses; while a p-value less than 0.05 was accepted as significant for each statistical test.

\section{Results}

A total number of three hundred and twelve (312) cancer patients participated in the study across the three centers. The socio demographic characteristics of the respondents are presented in Table 1.

Table 1. Distribution of Respondents by Gender, Age, Employment Status and Marital Status.

\begin{tabular}{lll}
\hline Variable & Frequency & Percent (\%) \\
\hline Gender: & 38 & \\
Male & 274 & 12.18 \\
Female & 312 & 87.82 \\
Total & & 100 \\
Age: & 3 & \\
$11-20$ years & 26 & 0.97 \\
21-30 years & 38 & 8.33 \\
31-40 years & 80 & 12.18 \\
$41-50$ years & 89 & 25.64 \\
51-60 years & 76 & 28.53 \\
61-70 years & 312 & 24.36 \\
Total & & 100 \\
Employment Status: & 50 & \\
Unemployed & 50 & 16.0 \\
Retired & 212 & 16.0 \\
Employed & 312 & 68.0 \\
Total & 242 & 100.0 \\
Marital Status: & 39 & 77.56 \\
Married Separated & 28 & 12.50 \\
Singled & 3 & 8.97 \\
Divorced & 312 & 0.97 \\
Total & & 100.0 \\
\hline
\end{tabular}

As shown in Table 1, most of the participants were females while the peak age group was 51-60 years age groups. The cancer sites of respondents are presented in Table 2 with majority of the respondents having breast cancer.

Table 2. Cancer types diagnosed among respondents.

\begin{tabular}{ll}
\hline Cancer type & Number $(\%)$ \\
\hline Breast & $143(45.7)$ \\
Cervix & $89(28.6)$ \\
Head \&Neck & $27(8.6)$ \\
Soft tissue sarcoma & $22(7.1)$ \\
GIT & $9(2.9)$ \\
Lung & $9(2.9)$ \\
Prostate & $4(1.4)$ \\
Skin & $4(1.4)$ \\
Total & $312(100)$ \\
\hline
\end{tabular}

Table 3 shows the regression analysis testing if the factors jointly predicted quality of life of cancer patients in the study population.

Table 3. Regression analysis of joint prediction of personal factors (gender, age, employment status and marital status) on quality of life of cancer patients.

\begin{tabular}{|c|c|c|c|c|c|c|}
\hline $\begin{array}{l}R=.754 \\
R^{2}=.568 \\
\text { Adj. } R^{2}=.563\end{array}$ & & & & & & \\
\hline Model & Sum of Squares & Df & Mean Square & $\mathbf{F}$ & Sig. ( $p$ value) & Remark \\
\hline Regression & 918.247 & 4 & & & & \\
\hline Residual & 697.240 & 307 & $\begin{array}{l}229.562 \\
2.271\end{array}$ & 101.078 & .0001 & Sig. \\
\hline
\end{tabular}


Table 3 revealed that there was a significant joint prediction of personal factors on quality of life of cancer patients in Southwestern Nigeria $\left(\mathrm{F}_{(4,307)}=101.078 ; \mathrm{R}=.754\right.$, $\mathrm{R}^{2}=.568$, Adj. $\left.\mathrm{R}^{2}=.563, p<.05\right)$; with about $56.3 \%$ of the variation accounted for by the independent variables. This implied that personal factors of age, gender, employment status and marital status had significant prediction on quality of life of cancer patients in Southwestern Nigeria, when taken together.

It was also tested if there was significant relative prediction of age, gender, employment status and marital status on quality of life of cancer patients in Southwestern Nigeria (Table 4).

Table 4. Regression analysis of relative prediction of personal factors on quality of life of cancer patients.

\begin{tabular}{llllll}
\hline Coefficient $^{\text {a }}$ & \multicolumn{2}{l}{} \\
\hline \multirow{2}{*}{ Model } & \multicolumn{2}{l}{ Unstandardized Coefficients } & Standardized Coefficients & \multirow{2}{*}{ T } & \\
\cline { 2 - 5 } & Beta & Std. Error & Beta & 7.923 & 0.00 \\
\hline (Constant) & 21.416 & 2.703 & -0.098 & -1.193 & 0.275 \\
Age & -0.033 & 0.03 & 0.035 & 0.618 & 0.537 \\
Gender & 0.493 & 0.798 & 0.069 & 1.172 & 0.242 \\
Marital status & 0.472 & 0.403 & -0.069 & -1.187 & 0.236 \\
Employment status & -0.427 & 0.36 & & & \\
\hline
\end{tabular}

Table 4 showed that age $(\beta=0.275, p>0.05)$, gender $(\beta=0.537, p>0.05)$, employment status $(\beta=0.236, p>0.05)$ and marital status $(\beta=0.242, p>.05)$ did not predict the quality of life of cancer patients in Southwestern Nigeria. This implied that age, gender, employment status and marital status independently had no significant prediction on quality of life of cancer patients in Southwestern Nigeria.

\section{Discussion}

Quality of life is an important index of cancer management in order to assess how the patients can function in daily routine roles.

The finding from the study of joint prediction of personal factors on quality of life of cancer patients revealed that, there was a significant joint prediction of personal factors on quality of life of cancer patients in Southwestern Nigeria. Literarily, it means that the linear combination of endogenous variables (personal factors) including age, gender, marital status and employment status significantly affected the criterion variable (quality of life of cancer patients). This implied that personal factors of age, gender, employment status and marital status had significant prediction on quality of life of cancer patients in Southwestern Nigeria, when taken together. It means that the combination of age, gender, employment and marital status could influence quality of life of cancer patients in Southwestern Nigeria.

The outcome of this study was in line with the finding of Bantema-Joppe et al. (2015) on age, which established that older cancer patients (70 years and above) have more comorbidities with lower health status, while young patients seem at higher risk for a large decrease in HRQoL after cancer treatment [14].

The finding of the study of relative prediction of personal factors on quality of life of cancer patients revealed that, age, gender, employment status and marital status did not predict the quality of life of cancer patients in Southwestern Nigeria. This implied that age, gender, employment status and marital status independently had no significant prediction on quality of life of cancer patients in Southwestern Nigeria. This report is similar to that of Zahra Sheikhalipour and colleagues (2019) who reported on QoL of women with cancer in Iran. In their report, age, marital status and occupation had no significant influence on QoL of the women. [15]. The outcome of this study on age was in contrast to the finding of Morrow and colleagues (2014) that, breast cancer has a greater impact on HRQoL in younger patients than in older ones [12].

In the same vein, the outcome of this study on employment status as a personal factor was in contrast to the finding of Worach-Kardas et al. (2014) that chronic medical conditions increase the risk for unemployment, which may result in a lower quality of life [16]. Similarly, the finding of the present study was in contrast with a meta-analysis which established that adult survivors of childhood cancer are twice as likely to be unemployed compared to healthy controls [17]. The finding from this study on gender was also contrast with the finding of Pud (2011) which established that gender differences in factors predicting QoL warrant different in clinical approaches to male and female patients [18]. The differences noted in this report compared with previous studies may be because the study included all categories of cancer patients in which some effects may cancels out a particular possible effect if considered under different cancer types (sites), age groups and gender sets. The report by Bantema-Joppe et al. (2015 that older cancer patients (70 years and above) have more co-morbidities with lower health status, while young patients seem at higher risk for a large decrease in HRQoL after cancer treatment is relevant [14]. This implies that in older patients with cancer, age may not readily come out as a factor that can predict QoL due to other comorbidities. Similarly, employment status and gender may not be relevant in that age group likewise marital status. These factors may be relevant if younger age groups were considered only. In this study, more than half of the study population were 51 years and above and the influence of age, employment and marital status in the younger ones would have been masked by the high number of those 51 years and above. Similarly, most of the participants were women (87\%) while those who were married were about $77 \%$ and over $66 \%$ 
were employed (Table 1). The influence of these factors on the other groups with lower proportions may not be noticeable due to low numbers represented.

\section{Conclusion}

The study showed that there was a significant joint prediction of personal factors (age, gender, employment status and marital status) on quality of life of cancer patients in Southwestern Nigeria while the factors of age, gender, employment status and marital status independently had no significant prediction on quality of life of cancer patients in Southwestern Nigeria. Stakeholders in the health care sector and oncology clinics in particular should endeavor to incorporate personal interventions in the management plan for cancer patients in Nigeria. Cancer site specific studies are warranted to characterize the influences of these factors based on specific cancer types.

\section{Conflicts of Interest}

The authors declare that they have no competing interests.

\section{References}

[1] American Cancer Society. Cancer Statistics [Internet]. Cancer Facts \& Figures 2020. 2020 [cited 2020 Feb 27]. Available from: https://www.cancer.org/content/dam/cancerorg/research/cancer-facts-and-statistics/annual-cancer-factsand-figures/2020/cancer-facts-and-figures-2020.pdf.

[2] International Agency of Research on Cancer (France). WHO [Internet]. Latest global cancer data. 2018 [cited 2020 Feb 27]. Available from:

https://www.who.int/cancer/PRGlobocanFinal.pdf.

[3] WHO. Cancer [Internet]. Key facts. 2020 [cited 2020 Feb 27]. Available from: https://www.who.int/news-room/factsheets/detail/cancer.

[4] Oguntayo O, Zayyan M, Kolawole A, Adewuyi S, Ismail H, Koledade K. Cancer of the cervix in Zaria, Northern Nigeria. Ecancermedicalscience [Internet]. 2011; 5: 219. Available from: http://www.ncbi.nlm.nih.gov/pubmed/22276061.

[5] Eguzo K. Cancer Care in Resource-Limited Settings: A Call for Action. J Cancer Sci Ther [Internet]. 2012; 04 (08): 223-6. Available from: https://www.omicsonline.org/cancer-care-inresource-limited-settings-a-call-for-action-19485956.1000145.php?aid=7536.

[6] Awodele O, Adeyomoye AA, Awodele DF, Fayankinnu VB, Dolapo DC. Cancer distribution pattern in south-western Nigeria. Tanzan J Health Res [Internet]. 2011 Apr [cited 2015 Jun 11]; 13 (2): 125-31. Available from: http://www.ncbi.nlm.nih.gov/pubmed/25566610.

[7] Jedy-Agba E, Curado MP, Ogunbiyi O, Oga E, Fabowale T, Igbinoba F, et al. Cancer incidence in Nigeria: a report from population-based cancer registries. Cancer Epidemiol
[Internet]. 2012 Oct [cited 2015 Dec 13]; 36 (5): e271-8. Available from: http://www.pubmedcentral.nih.gov/articlerender.fcgi?artid=34 $38369 \&$ tool $=$ pmcentrez\&rendertype $=$ abstract.

[8] Ian McDowell CN. Measuring health : a guide to rating scales and questionnaires. 2nd ed. New York: Oxford university press; 1996.

[9] Dolbeault S, Szporn A, Holland JC. Psycho-oncology: where have we been? Where are we going? Eur J Cancer [Internet]. 1999 Oct; 35 (11): 1554-8. Available from: http://www.ncbi.nlm.nih.gov/pubmed/10673961.

[10] Asuzu CC, Elumelu TN. Assessing cancer patients' quality of life and coping mechanisms in Radiotherapy Department of the University College Hospital, Ibadan. Psychooncology [Internet]. 2013 May; 10: 2306-12. Available from: http://doi.wiley.com/10.1002/pon.3290.

[11] Bresner L, Banach R, Rodin G, Thabane L, Ezzat S, Sawka AM. Cancer-related worry in Canadian thyroid cancer survivors. J Clin Endocrinol Metab [Internet]. 2015 Mar; 100 (3): 977-85. Available from: http://www.ncbi.nlm.nih.gov/pubmed/25393643.

[12] Morrow PK, Broxson AC, Munsell MF, Basen-Enquist K, Rosenblum CK, Schover LR, et al. Effect of age and race on quality of life in young breast cancer survivors. Clin Breast Cancer [Internet]. 2014 Apr; 14 (2): e21-31. Available from: http://www.ncbi.nlm.nih.gov/pubmed/24461458.

[13] Kirchhoff AC, Leisenring W, Krull KR, Ness KK, Friedman DL, Armstrong GT, et al. Unemployment among adult survivors of childhood cancer: a report from the childhood cancer survivor study. Med Care [Internet]. 2010 Nov; 48 (11): 1015-25. Available from: http://www.ncbi.nlm.nih.gov/pubmed/20940653.

[14] Bantema-Joppe EJ, de Bock GH, Woltman-van Iersel M, Busz DM, Ranchor A V, Langendijk JA, et al. The impact of age on changes in quality of life among breast cancer survivors treated with breast-conserving surgery and radiotherapy. Br J Cancer [Internet]. 2015 Feb 17; 112 (4): 636-43. Available from: http://www.ncbi.nlm.nih.gov/pubmed/25602967.

[15] Sheikhalipour Z, Ghahramanian A, Fateh A, Ghiahi R, Onyeka TC. Quality of Life in Women with Cancer and Its Influencing Factors. J Caring Sci [Internet]. 2019 Mar 1; 8 (1): 9-15. Available from: https://jcs.tbzmed.ac.ir/Abstract/jcs21478.

[16] Worach-Kardas H, Kostrzewski S. Quality of Life and Health State of Long - Term Unemployed in Older Production Age. Appl Res Qual Life [Internet]. 2014; 9: 335-53. Available from: http://www.ncbi.nlm.nih.gov/pubmed/24834137.

[17] de Boer AGEM, Verbeek JHAM, van Dijk FJH. Adult survivors of childhood cancer and unemployment: A metaanalysis. Cancer [Internet]. 2006 Jul 1; 107 (1): 1-11. Available from: http://www.ncbi.nlm.nih.gov/pubmed/16718655.

[18] Pud D. Gender differences in predicting quality of life in cancer patients with pain. Eur J Oncol Nurs [Internet]. 2011 Dec; 15 (5): 486-91. Available from: http://www.ncbi.nlm.nih.gov/pubmed/21256079. 